\title{
The relevance of socio-demographic and occupational variables for the assessment of work-related stress risk
}

\author{
Alessandro Marinaccio, Pierpaolo Ferrante, Marisa Corfiati, Cristina Di Tecco, Bruna M Rondinone, Michela Bonafede, \\ Matteo Ronchetti, Benedetta Persechino and Sergio lavicoli.
}

\begin{abstract}
Background: Work-related stress is widely recognized as one of the major challenges to occupational health and safety. The correlation between work-related stress risk factors and physical health outcomes is widely acknowledged. This study investigated socio-demographic and occupational variables involved in perceived risk of work-related stress.

Methods: The Italian version of the Health and Safety Executive Management Standards Indicator Tool was used in a large survey to examine the relationship between work-related stress risks and workers' demographic and occupational characteristics. Out of 8,527 questionnaires distributed among workers (from 75 organizations) 6,378 were returned compiled (74.8\%); a set of mixed effects models were adopted to test single and combined effects of the variables on work-related stress risk.

Results: Female workers reported lower scores on control and peer support and more negative perceptions of relationships and change at work than male workers, most of them with full-time contracts. Age, job seniority, and educational level appeared positively correlated with control at work, but negatively with job demands. Fixed-term workers had positive perceptions regarding job demands and relationships, but more difficulties about their role at work than permanent workers. A commuting time longer than one hour and shift work appeared to be associated with higher levels of risk factors for work-related stress (except for role), the latter having more negative effects, increasing with age.
\end{abstract}

Conclusions: The findings suggest that the assessment and management of work-related stress risk should consider specific socio-demographic and occupational risk factors such as gender, age, educational level, job status, shift work, commuting time, job contracts.

Keywords: Work-related stress, Risk factors, Italy, Epidemiological survey, Management standards indicator tool

\section{Background}

The assessment, prevention and control of work-related stress risk are widely recognized as one of the major challenges to occupational health and safety [1]. Workrelated stress is the second most common work-related health complaint among workers in the European Union (EU) and recent findings of large European surveys are consistent with a tendency to an increasing prevalence of work-related stress risks $[2,3]$. This might largely be due

\footnotetext{
* Correspondence: s.iavicoli@inail.it

Italian Workers' Compensation Authority, Research area, Occupational medicine department, Via di Fontana Candida 1, Rome 00100, Monteporzio Catone, Italy
}

(c) 2013 Marinaccio et al.; licensee BioMed Central Ltd. This is an open access article distributed under the terms of the Creative Commons Attribution License (http://creativecommons.org/licenses/by/2.0), which permits unrestricted use, distribution, and reproduction in any medium, provided the original work is properly cited. and work organization, with increasing use of nontraditional employment contracts and non-standard working hours, but also to other socio-economic and demographic factors indirectly influencing the world of work, such as economic globalization, an aging workforce and the increasing numbers of women entering the workforce.

There is also ample evidence that high-risk conditions for work-related stress have a detrimental impact on workers' health and safety, with a clear relation in particular with cardiovascular diseases [4], mental [5] and musculoskeletal disorders [6] and workers' psychosocial well-being 
$[7,8]$. Work-related stress can also affect an organization's productivity and competitiveness, with further impact on social and economic costs [1,9].

In the last decade several studies have provided evidence of certain key indicators of the social and occupational determinants of health $[10,11]$. As a consequence, there has been widespread pressure for the inclusion of those social and individual factors as determinants of workers' health and, according to Marmot [11], of health inequalities.

Increasing importance is being attached to socio-demographic and occupational variables in the assessment and management of work-related stress risk [1,2]. In a large multicenter European study, gender differences in work-related stress perception appeared stable across occupational groups but varied according to the geographical provenance [12]. Different patterns of generation of job stress were also described in men and women [13]. An inverted U-shaped relationship was found between age and job stress [14]. Emotional workload in younger people and lack of social support in older employees were associated with a higher risk of mental health complaints [15]. Older age and longer length of service were also associated with higher levels of stress and emotional exhaustion in a group of family physicians [16]. Low occupational status and educational level were associated with higher work-related stress risk in a large sample of French workers [17]. A large U.S. survey suggested that education could mask the effects of work-related stress on health, possibly in a gender-specific way [18]. Only limited evidence was found that shift-work with nights increased the effects of work stress on some health outcomes [19]. A recent critical review reported a negative association between short-term contracts and stress, very likely reflecting the efficiency of national welfare systems [20].

Despite the growing knowledge about these issues, further investigation is needed on the integrated role of socio-demographic and occupational factors on workrelated stress risk. The aim of this study was to explore the interaction effect among such characteristics and the perception of work-related stress risk, using a validated instrument. The study started from a larger research project to develop an integrated method for the assessment of work-related stress risk based on the UK Health and Safety Executive (HSE) Management Standards (MS) approach $[21,22]$ and reflecting the EU and Italian legislative and regulatory frameworks. The HSE Indicator Tool (IT) questionnaire has been proposed to evaluate seven areas of work design corresponding to specific risk factors for work-related stress: demands, control, managerial support, peer support, relationships, role, and change [21-23]. After a first step in which the Italian version of this questionnaire was validated [24], a study was conducted on a sample of over 6,000 Italian workers in order to examine the relationships between the seven MS areas and a number of workers' demographic and occupational characteristics. Specifically, the primary aim was to verify both main and the interactions effects of socio-demographic and occupational factors on the seven Indicator Tool risk factors for work-related stress and to produce explanatory hypotheses to test in the future. This analysis will also identify the socio-economic, demographic and occupational variables to be considered for the definition of homogeneous worker groups in the assessment of workrelated stress, as required by national and EU legislation.

\section{Methods}

\section{Participants and procedure}

Data were collected from March to September 2010, administering a structured questionnaire to obtain sociodemographic information about workers and occupational factors, and the validated Italian version of the HSE MS IT [21]. A convenient sample of organizations was selected taking into account the geographical locations of companies, their sectors of activity and sizes, with the collaboration of occupational safety and health key contact experts. Since no experimental procedures were conducted on study participants, ethical approval was not required [25]. For this study, approval was obtained by the social partners of each participant organization following preliminary information briefings. Workers' informed consent was thus obtained on the basis of specific information from their representatives. Enrolment of the workers, data collection and analysis were all done so that anonymity and privacy were ensured.

Questionnaires provided an introductory letter summarizing the study and giving contact information; they were compiled anonymously, on a voluntary basis. The contact experts distributed, collected and mailed the completed questionnaires to the Italian National Workers' Compensation Authority (INAIL). A self-reported questionnaire was given to every worker employed in the selected companies.

The study involved 75 organizations in the public (27\%) and private (73\%) sectors; only one company had branch offices outside headquarters. Out of the 8,527 questionnaires administered to workers 6,378 were returned compiled (74.8\% of total), the percentage of missing responses among IT items ranging from $0.89 \%$ to $2.57 \%$. As the percentage of missing data among socio-demographic and occupational factors was substantial (more than 30\%), its distribution was analyzed. For each socio-demographic and occupational variable a binary (missing/no-missing data) function was defined and a logistic model was used to test the association with all the other work-related risk factors. As no significant patterns were found, missing data were considered completely at random and the multi-variate analyses were based on the caselist after listwise delection $(n=4,123)$. Furthermore the differences between included and excluded participants on the seven IT scales were tested. 


\section{Instrument}

The HSE MS IT is a self-administered questionnaire used as a multi-dimensional measure of work-related stress risk. It consists of 35 items and two alternative response formats: a frequency format $(1=$ Never, $5=\mathrm{Al}$ ways) and an agree format ( $1=$ Strongly Disagree, $5=$ Strongly Agree). The seven risk factors measured are: demands (8 items) referring to issues like workload, work patterns; control (6 items) reflecting how much say a person has in the way they do the work; managerial support (5 items) measuring encouragement and sponsorship provided by the employer; peer support (4 items) measuring colleagues' encouragement and support; relationships (4 items) covering promoting a positive working atmosphere to avoid conflict; role (5 items) asking employees whether they understand their job and whether their employers ensure they do not have conflicting roles; and change (3 items) measuring how organizational change is managed and communicated at work. Questions for demands and relationships (negatively phrased) were reversed to conform to the other scales, with higher values indicating better performance. To verify the internal consistency of the sample the Cronbach's alpha coefficients were calculated for the seven HSE MS IT dimensions: demands (Cronbach's alpha =0.76), control (0.79), managerial support (0.80), peer support (0.82), relationships (0.81), role (0.77), change (0.70). Full details on this instrument can be found elsewhere [24].

\section{Statistical analysis}

The first two tables describe the statistical sample: Table 1 shows the distributions of socio-demographic and occupational variables, Table 2 the factor means and the standard deviation by gender. To investigate associations between socio-demographic and occupational variables with each IT risk-dimension, we adopted seven mixed effects models with random company-specific intercepts. These models can handle unbalanced data and correlated measures within companies and are described by the following equation:

$$
Y_{i}=(\text { fixed effects })+(\text { random effects })_{i}+(\text { error })_{i}
$$

for $i=1,2, \ldots, n$ (companies)

Both random effect (company effect) and residual (error) were assumed to be normally distributed with means zero and variances respectively $\sigma_{B}^{2}$ and $\sigma_{W}^{2}$.

As dependent variables $\left(Y_{i}\right)$, we considered the mean scores (range 1-5) for the IT subscales: demands, control, managerial support, peer support, relationships, role and change. Fixed effects (FEs) of the models were selected through the following procedure. For each IT subscale (response variable), FEs of all the available variables
Table 1 Socio-demographic and occupational factors of the workers' sample $(n=6,378)$ by gender*

\begin{tabular}{|c|c|c|c|c|}
\hline \multirow{3}{*}{ Age (yrs) } & \multicolumn{2}{|c|}{ Male } & \multicolumn{2}{|c|}{ Female } \\
\hline & \multirow[t]{2}{*}{$\mathbf{n}$} & \multirow[t]{2}{*}{$\%$} & \multirow[t]{2}{*}{$\mathrm{n}$} & \multirow[t]{2}{*}{$\%$} \\
\hline & & & & \\
\hline $18-30$ & 321 & 10.1 & 297 & 13.8 \\
\hline $31-50$ & 2,005 & 63.2 & 1,445 & 67.2 \\
\hline $50+$ & 846 & 26.7 & 408 & 19.0 \\
\hline Missing & 28 & - & 22 & - \\
\hline \multicolumn{5}{|l|}{ Marital status } \\
\hline Single & 812 & 25.5 & 617 & 28.6 \\
\hline Married & 2,162 & 67.7 & 1,298 & 60.0 \\
\hline Divorced/widowed & 216 & 6.8 & 246 & 11.4 \\
\hline Missing & 10 & - & 11 & - \\
\hline \multicolumn{5}{|l|}{ Educational level } \\
\hline Elementary/middle & 888 & 28.0 & 371 & 17.3 \\
\hline High school & 1,325 & 41.9 & 886 & 41.2 \\
\hline Master/degree & 955 & 30.1 & 893 & 41.5 \\
\hline Missing & 32 & - & 22 & - \\
\hline \multicolumn{5}{|l|}{ Occupational status } \\
\hline Blue-collar workers & 1,304 & 44.2 & 713 & 34.5 \\
\hline Clerks/professionals & 1,044 & 35.3 & 980 & 47.4 \\
\hline Manager & 606 & 20.5 & 373 & 18.1 \\
\hline Missing & 246 & - & 106 & - \\
\hline \multicolumn{5}{|l|}{ Job seniority } \\
\hline $0-5$ yrs & 665 & 22.4 & 589 & 28.3 \\
\hline 6-11 yrs & 706 & 23.8 & 571 & 27.5 \\
\hline $12-17$ yrs & 540 & 18.2 & 343 & 16.5 \\
\hline$>17$ yrs & 1,054 & 35.6 & 577 & 27.7 \\
\hline Missing & 235 & - & 92 & - \\
\hline \multicolumn{5}{|l|}{ Job contract } \\
\hline Permanent & 2,711 & 92.8 & 1,795 & 87.7 \\
\hline Fixed-term & 209 & 7.2 & 251 & 12.3 \\
\hline Missing & 280 & - & 126 & - \\
\hline \multicolumn{5}{|l|}{ Working hours } \\
\hline Full-time & 2,858 & 96.4 & 1,502 & 72.5 \\
\hline Part-time & 107 & 3.6 & 569 & 27.5 \\
\hline Missing & 235 & - & 101 & - \\
\hline \multicolumn{5}{|l|}{ Shift work } \\
\hline Day workers & 2,175 & 68.4 & 1,487 & 69.4 \\
\hline Shift workers & 450 & 14.1 & 384 & 17.9 \\
\hline Night workers & 558 & 17.5 & 272 & 12.7 \\
\hline Missing & 17 & - & 29 & - \\
\hline \multicolumn{5}{|c|}{ Commuting time to work } \\
\hline$\leq 60$ minutes & 1,984 & 78.0 & 1,502 & 77.9 \\
\hline$>60$ minutes & 561 & 22.0 & 427 & 22.1 \\
\hline Missing & 655 & - & 243 & - \\
\hline Total & 3,200 & & 2,172 & \\
\hline
\end{tabular}

*Gender is missing for 1,006 subjects. 
Table 2 Factors means and standard deviations of scales by gender

\begin{tabular}{lccccccc}
\hline & \multicolumn{3}{c}{ Female } & & \multicolumn{3}{c}{ Male } \\
\cline { 3 - 4 } & $\mathbf{n}$ & Mean & Std & & $\mathbf{n}$ & Mean & Std \\
\hline Demands & 2,168 & 3.50 & 0.64 & 3,192 & 3.51 & 0.62 \\
Control & 2,168 & 3.50 & 0.75 & 3,192 & 3.50 & 0.82 \\
Managerial support & 2,168 & $3.67^{*}$ & 0.80 & 3,192 & $3.61^{*}$ & 0.79 \\
Peer support & 2,167 & 3.77 & 0.75 & 3,192 & 3.78 & 0.73 \\
Relationships & 2,168 & $3.90^{*}$ & 0.76 & 3,192 & $4.01^{*}$ & 0.75 \\
Role & 2,168 & 4.35 & 0.56 & 3,193 & 4.36 & 0.58 \\
Change & 2,150 & $3.36^{*}$ & 0.82 & 3,176 & $3.31^{*}$ & 0.85 \\
\hline
\end{tabular}

${ }^{*}$ means significantly different by gender $(p<0.05)$.

were tested in a single effect model; the FEs that were significantly associated with at least one response variable were included in multivariate models and retested all together. Then the final models were obtained by excluding variables with no significant effect on any of the seven IT mean scores.

The independent variables included in the models were: gender (male, female), age (coded on three levels: 18-30, 31-50 and $>50$ years), educational level (coded on three levels: elementary/middle, high school and university degree), marital status (coded on three levels: single, married or divorced/widowed), occupational status (coded on three levels: blue-collar workers, clerks and managerial), job seniority (coded on four levels: 0-5, 6-11, 12-17 and >17 working years), job contract (coded on two levels: permanent and fixed-term), working hours (coded on two levels: full-time and part-time), shift work (coded on three levels: day workers, shift workers and night workers), commuting time to work and back (coded on two levels: $\leq 60$ and $>60$ minutes).

The interaction effects for which the scientific literature suggested deeper discussion and that were significantly associated with at least one IT subscale were considered. Working hours"gender [26]; shiftwork"job seniority [19] and occupational status*educational level [27] interaction effects were finally included in the models.

All the analyses were done using the statistical package SAS version 9.1. The level of statistical significance was set at 0.05 .

\section{Results}

Table 1 describes the socio-demographic and occupational characteristics of the 6,378 workers by gender. The male to female ratio was 1.47 . More than $60 \%$ of workers of both sexes were aged 31 to 50 years and most were married. About a third worked on shifts and about 16\% had flexible work patterns (part-time and/or fixed-term work). Fixed-term job contracts and mainly part-time work were more common for women (respectively $12.3 \%$ and $27.5 \%)$ than men (7.2\% and $3.6 \%)$.
Table 2 gives the descriptive statistics (mean and standard deviation) for the seven HSE IT areas. Mean scores for men ranged from 3.36 (change) to 4.35 (role), for women from 3.31 (change) to 4.36 (role). There were no significant differences by gender except for managerial support, relationships and change.

Women workers gave significantly lower scores on control and peer support scales and had more negative perceptions of relationships and change at work than men (Table 3), mainly among those with full-time contracts (Table 4). The oldest group ( $>50$ years) gave a higher score for control than those younger than 30 years. Both married and divorced/widowed people felt job demands more negatively than unmarried workers, though unmarried subjects had worse scores for control and role (Table 3).

Workers with high school or university education reported more positive perceptions of control but only those with a master degree had more negative perceptions of job demands than the less educated people. Blue-collar workers and clerks/managers scored less on control and reported more negative perceptions of relationships and the management and communication of change, but blue-collars perceived even lower job demands than managers. A positive correlation emerged between control and occupational status, with a mainly large difference between blue-collar workers and managers $(\beta=-0.51)$ (Table 3). Blue-collar workers and clerks with university education had less positive perceptions of demands than those with elementary/middle education, but higher scores in control. Blue-collar workers with a master degree had negative perceptions of their role compared to others whereas managers with higher education seemed to perceive a clearer role. A high educational level played a positive role in relation to relationships among white-collar workers (Table 4).

There was a weak positive correlation for role and control scores and job seniority, reaching significance only in the most experienced group ( $>17$ years in the current job). Workers with more than five years in the current job reported more negative perceptions of demands, relationships, peer and managerial support. Fixed-term contract workers had more positive perceptions of demands and relationships than permanent workers but felt their role less clearly (Table 3 ).

As regards commuting time, workers who spent more than an hour traveling to and from work had more negative perceptions of all the factors except role, than those who spent less than an hour (Table 3).

The negative effects of shift-work on all subscales except role was evident from the interaction with age; the scores were significantly lower for shift and/or night workers, mainly in the oldest groups (Table 4). Control and change scores were inversely related to age. Night work was significantly 
Table 3 Single effects of the workers' characteristics on the seven dimensions of perceived work-related stress (multiple mixed effects model)

\begin{tabular}{|c|c|c|c|c|c|c|c|c|c|c|c|c|c|c|}
\hline \multirow[b]{2}{*}{ Variables } & \multicolumn{2}{|c|}{ Demands } & \multicolumn{2}{|c|}{ Control } & \multicolumn{2}{|c|}{ Managerial support } & \multicolumn{2}{|c|}{ Peer support } & \multicolumn{2}{|c|}{ Relationships } & \multicolumn{2}{|c|}{ Role } & \multicolumn{2}{|c|}{ Change } \\
\hline & $\beta^{*}$ & $p$ & $\beta^{*}$ & $p$ & $\beta^{*}$ & $p$ & $\beta^{*}$ & $p$ & $\beta^{*}$ & $p$ & $\beta^{*}$ & $p$ & $\beta^{*}$ & $p$ \\
\hline \multicolumn{15}{|l|}{ Gender } \\
\hline Women & & ns & -0.09 & 0.003 & & ns & -0.11 & $<0.001$ & -0.13 & $<0.001$ & & ns & -0.06 & 0.046 \\
\hline Men (ref.) & 0 & - & 0 & - & 0 & - & 0 & - & 0 & - & 0 & - & 0 & - \\
\hline \multicolumn{15}{|l|}{ Age } \\
\hline$>51$ years & & ns & 0.10 & 0.048 & & ns & & ns & & ns & & ns & & ns \\
\hline $31-50$ years & & ns & & ns & & ns & & ns & & ns & & ns & & ns \\
\hline 18-30 years (ref) & 0 & - & 0 & - & 0 & - & 0 & - & 0 & - & 0 & - & 0 & - \\
\hline \multicolumn{15}{|l|}{ Marital status } \\
\hline Divorced/widowed & -0.09 & 0.012 & & ns & & ns & & ns & & ns & & ns & & ns \\
\hline Married & -0.05 & 0.034 & 0.06 & 0.027 & & ns & & ns & & ns & 0.08 & 0.001 & & ns \\
\hline Single (ref) & 0 & - & 0 & - & 0 & - & 0 & - & 0 & - & 0 & - & 0 & - \\
\hline \multicolumn{15}{|l|}{ Educational level } \\
\hline Master degree & -0.13 & 0.001 & 0.24 & $<0.001$ & & ns & & ns & & ns & & ns & & ns \\
\hline High school & & ns & 0.21 & $<0.001$ & & ns & & ns & & ns & & ns & & ns \\
\hline Elementary/middle (ref) & 0 & - & 0 & - & 0 & - & 0 & - & 0 & - & 0 & - & 0 & - \\
\hline \multicolumn{15}{|l|}{ Occupational status } \\
\hline Blue-collar & 0.13 & 0.002 & -0.51 & $<0.001$ & & ns & & ns & -0.14 & 0.004 & & ns & -0.22 & $<0.001$ \\
\hline Clerks/professionals & & ns & -0.31 & $<0.001$ & & ns & & ns & -0.17 & $<0.001$ & & ns & -0.23 & $<0.001$ \\
\hline Manager (ref) & 0 & - & 0 & - & 0 & - & 0 & - & 0 & - & 0 & - & 0 & - \\
\hline \multicolumn{15}{|l|}{ Job seniority } \\
\hline$>17$ years & -0.11 & $<0.001$ & 0.09 & 0.015 & -0.10 & 0.010 & -0.08 & 0.024 & & ns & 0.07 & 0.018 & & ns \\
\hline $12-17$ years & -0.11 & $<0.001$ & & ns & -0.14 & 0.001 & -0.13 & 0.001 & -0.14 & $<0.001$ & & ns & -0.10 & 0.018 \\
\hline $6-11$ years & & ns & & ns & -0.09 & 0.014 & -0.11 & 0.001 & -0.10 & 0.003 & & ns & & ns \\
\hline $0-5$ years (ref) & 0 & - & 0 & - & 0 & - & 0 & - & 0 & - & 0 & - & 0 & - \\
\hline \multicolumn{15}{|l|}{ Shift work } \\
\hline Night workers & -0.09 & 0.005 & -0.39 & $<0.001$ & & ns & & ns & -0.16 & $<0.001$ & & ns & -0.12 & 0.004 \\
\hline Shift workers & & ns & -0.22 & $<0.001$ & & ns & & ns & -0.10 & 0.004 & 0.08 & 0.003 & -0.08 & 0.039 \\
\hline Day workers (ref) & 0 & - & 0 & - & 0 & - & 0 & - & 0 & - & 0 & - & 0 & - \\
\hline \multicolumn{15}{|l|}{ Job contract } \\
\hline Fixed-term & 0.07 & 0.044 & & ns & & ns & & ns & 0.09 & 0.032 & -0.07 & 0.024 & & ns \\
\hline Permanent (ref) & 0 & - & 0 & - & 0 & - & 0 & - & 0 & - & 0 & - & 0 & - \\
\hline \multicolumn{15}{|l|}{ Commuting time to work } \\
\hline$\geq 60 \mathrm{~min}$. & -0.09 & $<0.001$ & -0.07 & 0.020 & -0.07 & 0.020 & -0.12 & $<0.001$ & -0.14 & $<0.01$ & & ns & -0.09 & 0.005 \\
\hline$<60 \min$ & 0 & - & 0 & - & 0 & - & 0 & - & 0 & - & 0 & - & 0 & - \\
\hline \multicolumn{15}{|l|}{ Working hours } \\
\hline Part-time & & ns & & ns & & ns & & ns & & ns & & ns & & ns \\
\hline Full-time (ref) & 0 & - & 0 & - & 0 & - & 0 & - & 0 & - & 0 & - & 0 & - \\
\hline
\end{tabular}

*The effects estimates $(\beta)$ are reported only for significant differences.

associated with negative perceptions of demands and relationships, particularly among the youngest workers. Those with individual missing data had more negative perceptions of the seven IT mean scores.

\section{Discussion}

This study explored the relationship between workers' individual characteristics and perceived risk for workrelated stress measured using the Italian validated version of the HSE IT. A large cross-sectional survey of Italian 
Table 4 Analysis of the effect of interaction between some workers' characteristics (multiple mixed effects model)

\begin{tabular}{|c|c|c|c|c|c|c|c|c|c|c|c|c|c|c|}
\hline \multirow[b]{2}{*}{ Interactive effects } & \multicolumn{2}{|c|}{ Demands } & \multicolumn{2}{|c|}{ Control } & \multicolumn{2}{|c|}{$\begin{array}{c}\text { Managerial } \\
\text { support }\end{array}$} & \multicolumn{2}{|c|}{ Peer support } & \multicolumn{2}{|c|}{ Relationships } & \multicolumn{2}{|c|}{ Role } & \multicolumn{2}{|c|}{ Change } \\
\hline & $\beta^{*}$ & $\mathrm{p}$ & $\beta^{*}$ & $p$ & $\beta^{*}$ & $\mathrm{p}$ & $\beta^{*}$ & $p$ & $\beta^{*}$ & $p$ & $\beta^{*}$ & $p$ & $\beta^{*}$ & $\mathrm{p}$ \\
\hline \multicolumn{15}{|l|}{ Among part-time } \\
\hline Women vs men & & ns & -0.18 & 0.029 & & ns & & ns & & ns & & ns & & ns \\
\hline \multicolumn{15}{|l|}{ Among full-time } \\
\hline Women vs men & -0.05 & 0.031 & -0.07 & 0.016 & & ns & -0.10 & $<0.001$ & -0.15 & $<0.001$ & & ns & -0.08 & 0.013 \\
\hline \multicolumn{15}{|l|}{ Among aged above 50 years } \\
\hline Night vs day workers & & ns & -0.45 & $<0.001$ & & ns & & ns & -0.17 & 0.011 & & ns & -0.18 & 0.026 \\
\hline Shift vs day workers & -0.11 & 0.036 & -0.48 & $<0.001$ & -0.23 & 0.001 & -0.15 & 0.019 & -0.21 & 0.001 & & ns & -0.28 & $<0.001$ \\
\hline \multicolumn{15}{|l|}{ Among aged $31-50$ years } \\
\hline Night vs day workers & & ns & -0.41 & $<0.001$ & & ns & -0.11 & 0.020 & -0.13 & 0.003 & & ns & -0.13 & 0.014 \\
\hline Shift vs day workers & & ns & -0.15 & $<0.001$ & & ns & & ns & & ns & 0.10 & 0.003 & & ns \\
\hline \multicolumn{15}{|l|}{ Among aged $18-30$ years } \\
\hline Night vs day workers & -0.20 & 0.005 & & ns & & ns & & ns & -0.27 & 0.002 & & ns & & ns \\
\hline Shift vs day workers & & ns & & ns & & ns & & ns & & ns & & ns & & ns \\
\hline \multicolumn{15}{|l|}{ Among blue-collars } \\
\hline Master degree vs elementary/middle & -0.10 & 0.050 & 0.21 & 0.001 & & ns & & ns & & ns & -0.10 & 0.035 & & ns \\
\hline High school vs elementary/middle & & ns & 0.08 & 0.036 & -0.11 & 0.004 & & ns & & ns & & ns & & ns \\
\hline \multicolumn{15}{|l|}{ Among clerks } \\
\hline Master degree vs elementary/middle & -0.15 & 0.008 & 0.31 & $<0.001$ & 0.16 & 0.024 & & ns & 0.18 & 0.006 & & ns & & ns \\
\hline High school vs elementary/middle & & ns & 0.37 & $<0.001$ & 0.14 & 0.036 & & ns & 0.19 & 0.002 & & ns & & ns \\
\hline \multicolumn{15}{|l|}{ Among managers } \\
\hline Master degree vs elementary/middle & & ns & & ns & & ns & & ns & & ns & & ns & & ns \\
\hline High school vs elementary/middle & & ns & & ns & & ns & & ns & & ns & 0.33 & 0.002 & & ns \\
\hline
\end{tabular}

*The effects estimates ( $\beta$ ) are reported only for significant differences.

companies was designed, covering a large part of the national economic sectors. The findings confirmed that both socio-demographic and occupational characteristics significantly influence work-related stress risk factors.

In compliance with Italian regulations, analysis of these characteristics contributes to the identification of "homogeneous" groups of workers for the assessment and management of work-related stress risk. The identification of particularly sensitive groups of workers, considering suitable individual and organizational aspects, is a key issue for the prevention policy recently introduced in EU and Italian legislation.

The study sample was in line with the composition of the overall Italian workforce, as compared with national statistics. In Italy in 2010 about $5 \%$ of male and 30\% of female employees worked part-time and the proportions of fixed-term workers varied from $11 \%$ for men to $15 \%$ for women. The percentage of subjects doing shift-work was comparable to that obtained from EU surveys among Italian workers [3].

As our findings confirmed, women had more negative perceptions of work-related stress risk factors than men, especially the full-time workers. This could well be due to gender role differentiation at work [28]. Traditionally, women have primarily a caretaking role and bear a higher burden of family-related responsibilities than men and that can make them more likely to feel strained by their job, particularly when they have trouble balancing work and family commitments, as in the case of full-time work [26]. In fact, by rebalancing work and family commitments through part- time work, the gender difference in perceived risk for work-related stress turned out to be irrelevant. It is worth noting that welfare deficiencies, exacerbated today by economic difficulties and the financial crisis, may also contribute to increasing the work-family imbalance.

We noted that married workers of both sexes perceived higher work demands. This too is likely to reflect the higher burden of family responsibilities on married workers compared to unmarried ones. As reported elsewhere [29], the weight of family responsibilities might lead to a potential work-home conflict that could reduce the individual's ability to cope with increasing demands at work. Unmarried workers perceived less autonomy in their 
job and greater role ambiguity than married ones. These findings are original but are very likely due to the closer social integration and acknowledgment of married people than single ones in the Italian social and cultural contexts.

A significant interaction was found between educational level and occupational status, since blue-collar workers with the highest level of education (i.e. master degree) perceived more job demands and role ambiguity. These findings might be explained by a phenomenon known as over-qualification or under-employment, a condition in which people have a level or type of education or skill that exceeds their job requirements [30]. The current changing nature of the world of work has resulted in increased unemployment and, in some cases, in large numbers of over-qualified workers. There is evidence of the effect of under-employment on workers' attitudes at work and physical and psychological health [27]. Moreover, blue-collar workers with higher education may perceive job demands and role ambiguity more negatively also because they are likely to be assigned more demanding jobs than their colleagues on account of their education and specialization.

Job seniority showed a positive relationship with control and role scores, confirming that the more experience a person has, the greater their autonomy and role awareness in their job [31]. At the individual level, a higher job tenure might balance the burden of responsibilities at work, emerging as higher perceived job demands. It is also worth noting that in our sample workers with higher seniority perceived a poorer quality of relationships with supervisors and colleagues and less social support at work than less senior ones. While job seniority increases, employees likely become more autonomous and the perceptions of supervisor and colleagues support may decrease. Furthermore, it is like we assist to a deterioration process of the relationships at work over time, but deeper investigation should test this hypothesis. Shift-workers perceived greater job demands, less autonomy at work and more conflicting relationships in the workplace, in line with previous findings [32]. Working on shifts and even more - working nights does call for a high degree of adaptation on the biological, social and behavioral levels [33], it can affect social relationships and lead to potentially important work-home interference [34]. However, shift-work appeared to be associated with slightly higher role clarity at work. Interpretation of these findings is complex and multifaceted, possibly including the influence on the clarity of role and the absence of potential role conflicts. As for the possible combined effects of shift-work and aging on workers' health and wellbeing, data are still contrasting. We found an interactive effect of aging and shift-work on most work-related stress risk areas. The negative perceptions among older workers might reflect their lower tolerance of shift-work, mainly involving greater sensitivity to physical health disorders and sleep problems [35]. However, age did not seem to boost the detrimental effect of shift-work, and particularly of night work, on relationships and support at work, possibly because of the higher experience among elderly workers [36].

The relationship between commuting time and perceived risk for work-related stress is widely acknowledged, like the association with physical and psychological health outcomes such as musculoskeletal disorders, cardiovascular diseases, anxiety and sleep disorders [37-39]. Long commuting time to work also reduces productivity and job satisfaction, mostly through enhancement of the perception of work-related stress risk factors [40,41]. In line with the literature, our findings confirm the negative role of commuting particularly on demands and control (where the management of working hours is extremely important) and on social support and relationships at work. No negative influence of commuting time was found on workers' perceptions of their role (role clarity and conflict). This is presumably due to the fact that role is more associated with aspects related to the job design than to the job schedule.

Finally, those with a fixed-term contract had more positive perceptions of demands and relationships at work but less positive perceptions of their role than permanent workers. International studies on job contracts, fixed-term work conditions and health reported contrasting findings [20]. Several studies have indeed demonstrated that other factors (e.g. welfare policies, more flexibility in organizing work) may moderate the negative consequences on workers' health related to fixed-term employment. However, a fixed-term contract may, in some cases, make workers feel less involved in their company, with negative consequences for role clarity.

\section{Limitations and future perspectives}

One of the main limitations relies in the high proportion of missing data on individual characteristics. As in other self-reported studies, privacy concerns and the need for anonymity can lead to a large number of missing data. In our sample, workers who did not report their individual characteristics had more negative perceptions of the seven risk areas (assessed from IT mean scores). This suggests a personal decision to omit some socio-demographic and occupational information to avoid being identified. Nevertheless, the distribution of missing data among individual characteristics was completely at random. The analysis of factors influencing missing data is beyond the scope of the present study and it could be better investigated in the future.

A second limitation relates to the self-reported nature of our data: the findings may contain some bias on account of the common method variance. However, our aim was 
primarily to investigate the perceptions of psychosocial risks, which by definition are aspects that only the individual can report [42]. Future studies should investigate some objective indicators besides workers' perceptions in order to firmly anchor our findings.

The lack of data on ethnicity is another limitation and needs to be considered in the future, particularly considering the growing presence of immigrants in the Italian and overall European workforce.

\section{Conclusions}

Our findings illustrate the importance of socio-demographic and occupational variables for work-related stress risk factors. The most susceptible groups were female workers, for whom part -time work is one way of reducing the difficulties of balancing work and family commitments, better-educated workers, especially those who are overqualified for the jobs assigned, and shift workers, especially older ones.

Finally, commuting time was confirmed as having an effect on work-related stress risk, whereas part-time work, especially for women, and fixed-term contracts had potentially protective effects.

It may be reasonable to conclude that the assessment and management of work-related stress risk should take into account the relations with all the social, demographic, and occupational factors involved. Analysis of these variables is particularly important in the light of the European legislation on safety and health at work, concerning the obligation to assess the risk of work-related stress, because it can provide useful information as a basis for identifying specific groups of workers at risk. We would warmly suggest focusing on interventions aimed at managing work-related stress risk in these groups, such as job scheduling, transportation demand, training for less experienced workers, and strategies for reducing work-home conflict.

\section{Competing interests}

The authors declare that they have no competing interests.

\section{Authors' contributions}

AM participated to conceive the study and to define its design, participated in the statistical analysis and to draft the manuscript. PF participated to define the design of the study, performed the statistical analysis and participated to draft the manuscript. MC, CDT, MB, MR participated to conceive the study and to define its design, participated in the statistical analysis and to draft the manuscript. BMR, BP participated to conceive the study and to define its design. SI conceived the study and defined its design, participated to draft the manuscript. All authors read and approved the final manuscript.

\section{What this paper adds}

This study shows that age, sex, job seniority, commuting time, shift work, job contract and occupational status all influence work-related risk factors;

The assessment and management of work-related stress risk should consider specific socio-demographic and occupational variables;

This study helps define groups of workers at risk to whom specific interventions could be targeted for the prevention of work-related stress and individual and organizational health problems.
Received: 29 November 2012 Accepted: 20 November 2013

Published: 10 December 2013

\section{References}

1. Leka S, Jain A: Health impact of psychosocial hazards at work: an overview. Geneva: World Health Organization; 2010.

2. European Agency for safety and health at work: Management of psychosocial risks at work: An analysis of the findings of the European Survey of Enterprises on New and Emerging Risks (ESENER). Luxembourg: Publications Office of the European Union; 2012

3. European Foundation for the Improvement of Living and Working Conditions: Fifth European Working Conditions Survey. Luxembourg: Publications Office of the European Union; 2012.

4. Kivimäki $M$, Virtanen $M$, Elovainio $M$, Kouvonen $A$, Väänänen $A$, Vahtera J: Work stress in the etiology of coronary heart disease-a meta-analysis. Scand J Work Env Health 2006, 32:431-442.

5. Nieuwenhuijsen K, Bruinvels D, Frings-Dresen M: Psychosocial work environment and stress-related disorders, a systematic review. Occup Med 2010, 60:277-286.

6. Bongers PM, ljmker S, van den Heuvel S, Blatter BM: Epidemiology of work related neck and upper limb problems: psychosocial and personal risk factors (part I) and effective interventions from a bio behavioural perspective (part II). J Occup Rehabil 2006, 16:279-302.

7. Kerr R, McHugh M, McCrory M: HSE management standards and stress-related work outcomes. Occup Med 2009, 59:574-579.

8. Guidi S, Bagnara S, Fichera GP: The HSE indicator tool, psychological distress and work ability. Occup Med 2012, 3:203-209.

9. Cooper $\mathrm{CL}$, Liukkonen P, Cartwright S: Stress prevention in the workplace: assessing the costs and benefits to organisations. European Foundation for the Improvement of Living and Working Conditions: Dublin; 1996.

10. Wilkinson R, Marmot M: Social determinants of health: the solid facts. 2nd edition. WHO Regional office for Europe: Copenhagen; 2003.

11. Marmot M: Fair Society, Healthy Lives. (The Marmot Review). Strategic review of Health Inequalities in England post-2010. London: Marmot Review; 2010. http://www. instituteofhealthequity.org/projects/fair-society-healthylives-the-marmot-review.

12. de Smet P, Sans S, Dramaix M, Boulenguez $C$, de Backer G, Ferrario M, Cesana G, Houtman I, Isacsson SO, Kittel F, Ostergren PO, Peres I, Pelfrene E, Romon M, Rosengren A, Wilhelmsen L, Kornitzer M: Gender and regional differences in perceived job stress across Europe. Eur J Public Health 2005, 15:536-545.

13. Rivera-Torres P, Araque-Padilla RA, Montero-Simó MJ: Job stress across gender: the importance of emotional and intellectual demands and social support in women. Int J Environ Res Public Health 2013, 10:375-389.

14. Rauschenbach $C$, Hertel $G$ : Age differences in strain and emotional reactivity to stressors in professional careers. Stress Health 2011, 27:48-60.

15. Zoer I, Ruitenburg MM, Botje D, Frings-Dresen MH, Sluiter JK: The associations between psychosocial workload and mental health complaints in different age groups. Ergonomics 2011, 10:943-952.

16. Stanetić $\mathrm{K}$, Tesanović $\mathrm{G}$ : Influence of age and length of service on the level of stress and burnout syndrome. Med Preg/ 2013, 3-4:153-162.

17. Niezborala M, Marquie JC, Baracat B, Esquirol Y, Soulat JM: Job stress and occupational status in a French cohort. Rev Epidemiol Sante Publique 2003, 6:607-616.

18. Qiu H, Bures R, Shehan $C L$ : The inconsistent mediating effects of psychosocial work characteristics on the education-health relationship. Soc Sci Med 2012, 8:1539-1546.

19. Conway PM, Campanini P, Sartori S, Dotti R, Costa G: Main and interactive effects of shiftwork, age and work stress on health in an Italian sample of healthcare workers. Appl Ergon 2008, 39:630-639.

20. Kim IH, Muntaner C, Vahid Shahidi F, Vives A, Vanroelen C, Benach J: Welfare states, flexible employment, and health: a critical review. Health Policy 2012, 104:99-127.

21. Cousins R, Mackay CJ, Clarke SD, Kelly C, Kelly PJ, McCaig RH: Management standards and work-related stress in the UK: practical development. Work \& Stress 2004, 18:113-136.

22. Mellor N, Mackay C, Packham C, Jones R, Palferman D, Webster S, Kelly P: Management Standards' and work-related stress in Great Britain: progress on their implementation. Safety Sci 2011, 49:1040-1046.

23. Edwards JA, Webster S, Van Laar D, Easton S: Psychometric analysis of the UK health and safety Executive's management standards work-related stress indicator tool. Work \& Stress 2008, 22:96-107. 
24. Rondinone BM, Persechino B, Castaldi T, Valenti A, Ferrante P, Ronchetti M, lavicoli S: Work-related stress risk assessment in Italy: the validation study of health safety and executive indicator tool. G Ital Med Lav Ergon 2012, 34:392-399.

25. Italian Legislative Decree n. 211 of 24 June 2003: Transposition of Directive 2001/20/EC relating to the implementation of good clinical practice in the conduct of clinical trials on medicinal products for clinical use. Official Journal 2003. no. 184, ordinary supplement no. 130.

26. Beach B: Integrated work and family life. The home-working family. Albany: State University of New York Press; 1989.

27. Maynard DC, Joseph TA, Maynard AM: Underemployment, job attitudes, and turnover intentions. J Organ Behav 2006, 27:509-536.

28. Addae HM, Johns G: National culture and perceptions of absence legitimacy In Voluntary employee withdrawal and inattendance: A current perspective. Edited by Koslowsky M, Krausz M. New York: Kluwer/Plenum; 2002:21-51.

29. Byron K: A meta-analytic review of work-family confict and its antecedents. J Vocat Behav 2005, 67:169-198.

30. Feldman DC: The nature, antecedents, and consequences of underemployment. J Manage 1996, 22:385-407.

31. Robertson A, Tracy CS: Health and productivity of older workers. Scand J Work Environ Health 1998, 24:85-97.

32. Bøggild $H$, Burr $H$, Tüchsen $F$, Jeppesen $H J$ : Work environment of Danish shift and day workers. Scand J Work Environ Health 2001, 27:97-105.

33. Costa G: Shift work and occupational medicine: an overview. Occup Med (Lond) 2003, 53:83-88.

34. Demerouti E, Geurts SA, Bakker AB, Euwema M: The impact of shiftwork on work-home conflict, job attitudes and health. Ergonomics 2004, 47:987-1002.

35. Costa G, Di Milia L: Aging and shift work: a complex problem to face. Chronobiol Int 2008, 25:165-181.

36. Härmä MI, IImarinen JE: Towards the 24-hour society-new approaches for aging shift workers? Scand J Work Environ Health 1999, 25:610-615.

37. Stokols D, Novaco RW, Stokols J, Campbell J: Traffic congestion, Type-A behavior and stress. J App Psychol 1978, 63:467-480.

38. Stutzer A, Frey BS: Stress that Doesn't Pay: the commuting Paradox! Scand J Econ 2008, 110:339-366.

39. Novaco RW, Stokols D, Campbell J, Stokols J: Transportation, stress, and community psychology. Amm J Commun Psychol 1979, 7:361-380.

40. Koslowsky M, Kluger AN, Reich M: Commuting Stress: Causes, Effects, and Methods of Coping. New York: Plenum Press; 1995.

41. Schaeffer MH, Street SW, Singer JE, Baum A: Effects of control on stress reaction of commuters. J App Soc Psychol 1988, 18:944-957.

42. Caprara GV, Cervone D: Personality: Determinants, Dynamics, and Potential. Cambridge, UK: Cambridge University Press; 2000.

doi:10.1186/1471-2458-13-1157

Cite this article as: Marinaccio et al:: The relevance of socio-demographic and occupational variables for the assessment of work-related stress risk. BMC Public Health 2013 13:1157.

\section{Submit your next manuscript to BioMed Central and take full advantage of:}

- Convenient online submission

- Thorough peer review

- No space constraints or color figure charges

- Immediate publication on acceptance

- Inclusion in PubMed, CAS, Scopus and Google Scholar

- Research which is freely available for redistribution 